\title{
Genetic basis of intracranial aneurysm formation and rupture: clinical implications in the postgenomic era
}

\author{
Nardin Samuel, MD, PhD, ${ }^{1}$ and Ivan Radovanovic, MD, PhD ${ }^{1,2}$ \\ 1Division of Neurosurgery, Department of Surgery, University of Toronto; and 2Division of Neurosurgery, Toronto Western \\ Hospital, University Health Network, Toronto, Ontario, Canada
}

\begin{abstract}
OBJECTIVE Despite the prevalence and impact of intracranial aneurysms (IAs), the molecular basis of their pathogenesis remains largely unknown. Moreover, there is a dearth of clinically validated biomarkers to efficiently screen patients with IAs and prognosticate risk for rupture. The aim of this study was to survey the literature to systematically identify the spectrum of genetic aberrations that have been identified in IA formation and risk of rupture.

METHODS A literature search was performed using the Medical Subject Headings (MeSH) system of databases including PubMed, EMBASE, and Google Scholar. Relevant studies that reported on genetic analyses of IAs, rupture risk, and long-term outcomes were included in the qualitative analysis.

RESULTS A total of 114 studies were reviewed and 65 were included in the qualitative synthesis. There are several well-established mendelian syndromes that confer risk to IAs, with variable frequency. Linkage analyses, genome-wide association studies, candidate gene studies, and exome sequencing identify several recurrent polymorphic variants at candidate loci, and genes associated with the risk of aneurysm formation and rupture, including ANRIL (CDKN2B-AS1, 9p21), ARGHEF17 (11q13), ELN (7q11), SERPINA3 (14q32), and SOX17 (8q11). In addition, polymorphisms in eNOS/ NOS3 (7q36) may serve as predictive markers for outcomes following intracranial aneurysm rupture. Genetic aberrations identified to date converge on posited molecular mechanisms involved in vascular remodeling, with strong implications for an associated immune-mediated inflammatory response.
\end{abstract}

CONCLUSIONS Comprehensive studies of IA formation and rupture have identified candidate risk variants and loci; however, further genome-wide analyses are needed to identify high-confidence genetic aberrations. The literature supports a role for several risk loci in aneurysm formation and rupture with putative candidate genes. A thorough understanding of the genetic basis governing risk of IA development and the resultant aneurysmal subarachnoid hemorrhage may aid in screening, clinical management, and risk stratification of these patients, and it may also enable identification of putative mechanisms for future drug development.

https://thejns.org/doi/abs/10.3171/2019.4.10.3171/2019.4.FOCUS19204

KEYWORDS intracranial aneurysm; gene; genetic; risk; polymorphism

I NTRACRANIAL aneurysms (IAs) are pathological dilatations of cerebral vasculature, most commonly occurring at bifurcations of major intracranial arteries, and are estimated to occur in up to $6 \%$ of adults worldwide. ${ }^{54}$ Approximately $2 \%$ of these aneurysms ultimately rupture, as inferred from the cumulative incidence of aneurysmal subarachnoid hemorrhage (aSAH) ${ }^{54}$ Unruptured aneurysms may be detected incidentally through cranial imaging for trauma or alternate pathologies, or through deliberate screening of high-risk individuals, such as those with a family history of IAs. The most devastating consequence of IA rupture is aSAH, with an impact ranging from mild symptoms to severe disability or mortality. The mortality rate associated with aSAH is estimated to be approximately one-third to one-half of patients, and this figure has remained relatively unchanged in the past several decades. ${ }^{51}$ The management of unruptured IAs has been the source of intensive study and debate, and requires meticulous consideration of the risk of rupture along with the perioperative risks of intervention. ${ }^{22}$

ABBREVIATIONS ADPKD = autosomal dominant polycystic kidney disease; aSAH = aneurysmal subarachnoid hemorrhage; $\mathrm{DCl}=$ delayed cerebral ischemia; $\mathrm{EDS}=$ Ehlers-Danlos syndrome; eNOS = endothelial nitric oxide synthase; GWAS = genome-wide association studies; IAs = intracranial aneurysms; LDS = Loeys-Dietz syndrome; MMPs = matrix metalloproteases; NF1 = neurofibromatosis type 1; TSC = tuberous sclerosis complex; WES = whole-exome sequencing.

SUBMITTED March 1, 2019. ACCEPTED April 24, 2019.

INCLUDE WHEN CITING DOI: 10.3171/2019.4.10.3171/2019.4.FOCUS19204. 


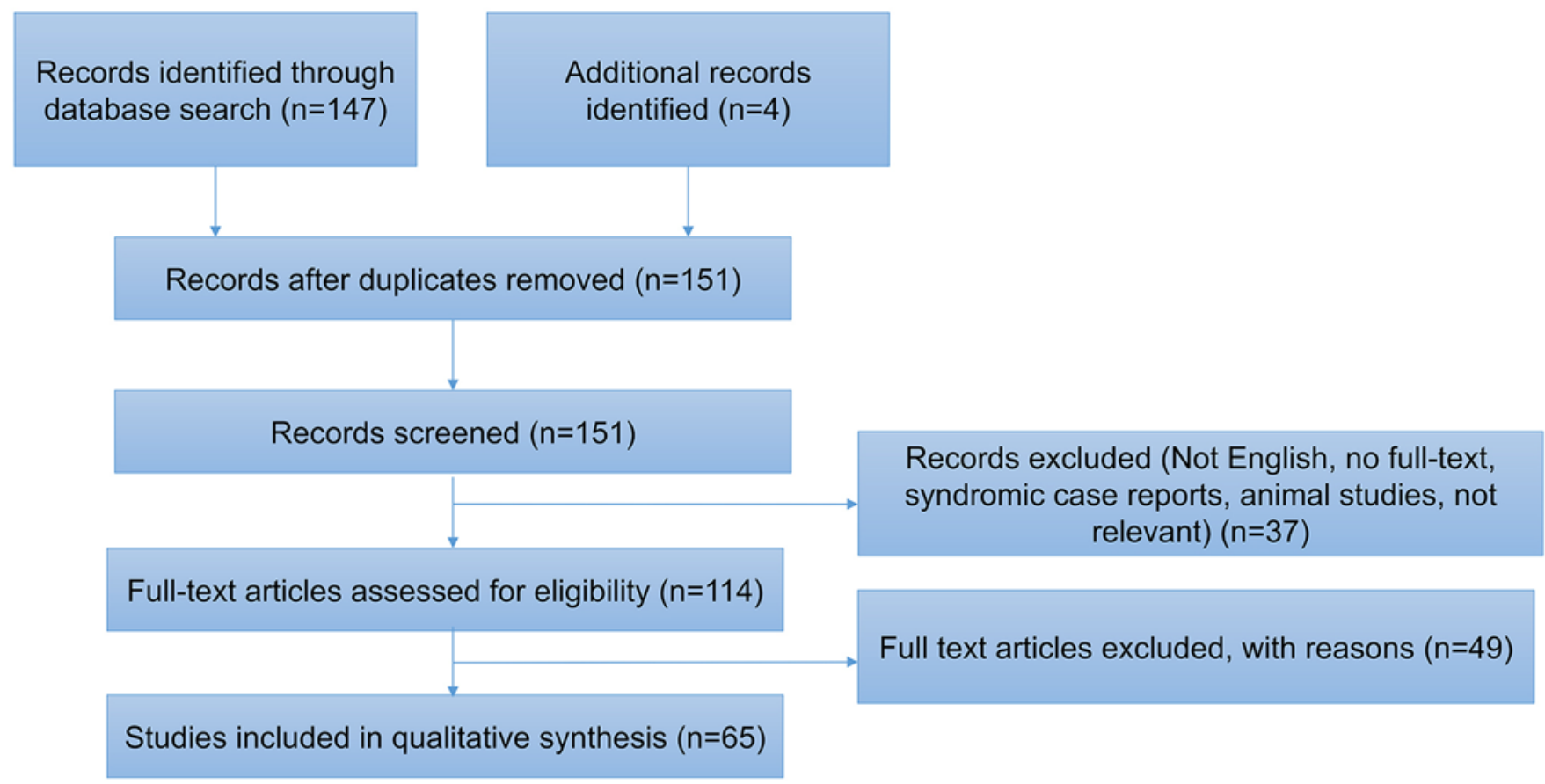

FIG. 1. PRISMA-style flowchart for record screening and inclusion for review.

However, despite the prevalence and impact of IAs, their pathogenesis remains largely unknown. In addition, although the management of patients with both ruptured and unruptured IAs is highly nuanced, clinical decision-making in this patient population has not involved prognostic markers. Intensive clinical research has been undertaken to better define the natural history of unruptured IAs, yet screening for IAs to assess risk of aSAH has not been implemented because biomarkers have not been clinically validated. Similarly, although the risk of rupture of IAs has been widely studied and is dependent on several aneurysm-related and patient-specific variables, genetic interactions with these variables have not yet been validated.

A heritable contribution to aneurysm formation and rupture is estimated to be present in up to $40 \%$ of cases, with the remaining cases probably attributable to geneenvironment interactions that lead to sporadic IA formation. ${ }^{35}$ Familial clustering of IAs in the general population, as well as the association with mendelian disorders in IAs provide strong evidence for genetic underpinnings of this disease.$^{58}$ Meta-analyses of studies in the literature support the theory that IAs are caused by significant genetic heterogeneity and polygenic contributions to the risk of formation and rupture. ${ }^{57}$ Moreover, studies have shown that there is an approximately 17 times greater risk of aneurysm rupture in familial IAs as compared with sporadic IAs, when matched for size and location. ${ }^{13}$ Much like other areas of medicine, including oncology, where thorough genetic analyses have enabled identification of clinically relevant subtypes, there is evidence for a genetic basis in subpopulations of aneurysms that are more prone to rupture than others, depending on their size and history of formation. ${ }^{30}$
In order to continue to advance the field of vascular neurosurgery, new therapies informed by the mechanisms of disease are imperative. An understanding of the genetics and mechanisms governing IA pathophysiology can therefore guide future treatment and management of this challenging clinical entity. Mechanisms involving inflammatory responses and vascular remodeling have been proposed to comprise the basis of genetic dysregulation, and familial studies have provided support in this regard. Accordingly, this report details a review of genetic studies on IAs in the literature, highlights putative disease-related genes and posited mechanisms, and discusses the implications for clinical applications.

\section{Methods}

A literature search was performed using the Medical Subject Headings (MeSH) system of databases including PubMed, EMBASE, and Google Scholar. There were no date restrictions imposed. All articles that were included contained the terms "Intracranial aneurysm" OR "brain aneurysm" AND "gene" OR "genetic" OR "SNPs" [single nucleotide polymorphisms]. A PRISMA-style flowchart of the search findings is detailed in Fig. 1. One hundred fortyseven articles were identified from this initial screen and another 4 articles were obtained from a survey of other databases using the same search terms. There were no instances of duplicate studies. Of the 151 records screened, 49 were excluded. Only English articles were included, and reports on animals or animal models (37 articles) were not included in the final list of studies.

In accordance with the Cochrane Risk of Bias Tool, study bias risk was assessed. Selection bias was addressed by including studies based on the criteria outlined: studies 
TABLE 1. Literature review of autosomal dominant mendelian syndromes associated with risk of IAs

\begin{tabular}{|c|c|c|c|}
\hline Authors \& Year & Gene & Associated Syndrome & Known Implications \& Disease Prevalence \\
\hline $\begin{array}{l}\text { Kim et al., } 2016 \\
\text { Schievink et al., } 1994\end{array}$ & COL3A1 & Vascular EDS (type IV) & $\begin{array}{l}\text { IAs have been reported in both classic \& nonclassic forms of EDS; patients w/ vascular } \\
\text { subtype of EDS are at highest risk for IA formation (12\%). }\end{array}$ \\
\hline $\begin{array}{l}\text { Conway et al., } 2001 \\
\text { Kim et al., } 2016\end{array}$ & FBN1 & Marfan syndrome & $\begin{array}{l}\text { Study results are conflicting regarding estimate of prevalence. Earlier reports failed to } \\
\text { identify an association btwn IAs \& Marfan syndrome on autopsy; estimated prevalence } \\
\text { of at least } 1 \text { aneurysm is } \sim 14 \% \text {. }\end{array}$ \\
\hline \multirow{2}{*}{$\begin{array}{l}\text { Rossetti \& Harris, } \\
2013\end{array}$} & PKD1 & \multirow[t]{2}{*}{ ADPKD } & Prevalence of $12.4 \%$ of IAs in general ADPKD population, w/ an age-dependent increase \\
\hline & PKD2 & & $\begin{array}{l}\text { of prevalence, w/ a peak of } 23.3 \% \text { in patients older than } 60 \text { yrs. } \\
\text { Risk is strongly associated w/ family history of rupture. The estimated prevalence of } \\
\text { ulAs in patients w/ ADPKD w/ a family history of IAs \&/or SAH is } 21.2 \% \text {, whereas the } \\
\text { estimated prevalence of ulAs in ADPKD patients w/o such a history is } 6.3 \% \text {. }\end{array}$ \\
\hline \multirow{3}{*}{$\begin{array}{l}\text { Kim et al., } 2016 \\
\text { Loeys et al., } 2006 \\
\text { Rodrigues et al., } 2009\end{array}$} & SMAD3 & \multirow[t]{3}{*}{ LDS } & \multirow{3}{*}{$\begin{array}{l}\text { Intracranial bleeding secondary to vascular pathology is the 3rd leading cause of death in } \\
\text { patients w/ LDS; prevalence of IAs estimated to range btwn } 10 \% \& 28 \% \text {. }\end{array}$} \\
\hline & TGFBR1 & & \\
\hline & TGFBR2 & & \\
\hline
\end{tabular}

ulAs = unruptured IAs.

reporting on genetic analyses were included and those on expression alone were omitted. Systematic reviews, familial studies, clinical case series, whole-exome sequencing (WES), whole transcriptome sequencing, genome-wide association studies (GWAS), and candidate gene studies were all included. Reviews were also included in the qualitative analysis. Case reports of IAs arising in the context of rare syndromic clinical entities were excluded. One study reporting on genetic risk of de novo aneurysm formation secondary to an iatrogenic complication was also excluded. A total of 65 articles met sufficient criteria to be included in the qualitative analysis. The most recent MeSH search was performed on February 15, 2019. Polymorphic variants were tabulated if statistical significance reached a $\mathrm{p}$ value less than $1.0 \mathrm{e}^{-6}$. For candidate gene studies, a minimum of 500 combined samples derived from cases and controls was used for the genes to be tabulated, a cutoff consistent with other reviews and meta-analyses in the literature. Candidate variants that reached borderline statistical significance were not included. There were no sample size restrictions for whole-exome- or wholegenome-based studies.

\section{Results}

\section{Genetic Aberrations Identified Through Familial and Genome-Directed Studies}

Aneurysm Formation: Known Genes Associated With Mendelian Syndromes

There are numerous well-recognized mendelian disorders that confer an increased risk of developing IAs. Over the past few decades, there has been reconsideration of the concept of single gene mutations causing single clinical phenotypes and instead, a paradigm shift toward conceptualization of interactions between single gene mendelian phenotypes and allelic variants at other chromosomal loci, or so-called transacting regulatory elements. As a result, traditional mendelian views of disease inheritance have shifted from dichotomous disease states toward a continuous spectrum. ${ }^{49}$ The etiology of this variability remains unclear; however, the high degree of pleiotropy of IA formation within and across genetic syndromes is clinically evident.

Approaches to identifying IA-related genes include linkage analysis in large families and candidate gene approaches. ${ }^{70}$ Familial studies have largely focused on candidate genes that play a role in maintenance and repair of the arterial wall (Table 1). ${ }^{59}$ Perhaps one of the most well-characterized mendelian syndromes conferring an increased risk to IAs is autosomal dominant polycystic kidney disease (ADPKD), and in fact this disease imparts the highest risk of IAs among the other mendelian syndromes associated with a higher risk of IA formation than the general population. ${ }^{50}$ ADPKD is caused by mutations in $P K D 1$ in $85 \%$ of cases and by $P K D 2$ mutations in the remaining $15 \%$. The renal-specific disease spectrum of ADPKD is highly variable, as is the risk of IAs. IAs are the most life-threatening feature of this syndrome and have an estimated prevalence of $12.4 \%$, with a peak prevalence of $23.3 \%$ in patients older than 60 years of age. ${ }^{56}$ In some instances, devastating SAH may be the first presentation in a patient with ADPKD, as in other mendelian syndromes. ${ }^{5,29}$ Screening for IAs is typically recommended in patients with known ADPKD who are older than 30 years, and in normotensive individuals in this patient population. ${ }^{66}$ Of note, the PKD1 gene resides at $16 \mathrm{p} 13$, the same locus harboring the TSC2 gene, in which mutations are associated with tuberous sclerosis complex (TSC). Contiguous genetic aberrations encompassing these genes, such as deletions, have been identified, which thereby lead to a concurrent syndrome of ADPKD and TSC. ${ }^{16,46}$ This rare subset of patients is at a much higher risk of developing IAs, demonstrating the impact of modifier genes on mendelian phenotypes.

IAs have been described in a number of mendelian connective tissue disorders, including vascular EhlersDanlos syndrome (EDS, formerly referred to as EhlersDanlos type IV) associated with mutations in COL $3 \mathrm{Al}$; Loeys-Dietz syndrome (LDS) associated with pathogenic mutations in genes involved in the transforming growth factor $\beta$ (TGF $\beta$ ) pathway; and Marfan syndrome associ- 
ated with mutations in $F B N 1^{33}$ (Table 1). As outlined in greater detail below, the pathological mechanisms underlying this susceptibility are probably related to structural vulnerabilities in the intracranial vasculature as a result of malfunction of the respective genes. With regard to EDS, consensus guidelines for screening are lacking, and are often considered on a patient-specific basis. LDS is characterized by severe vascular defects predominantly affecting the arterial system, with a high risk of aneurysmal arterial hemorrhage or dissection at a young age. ${ }^{44}$ Intracranial bleeding secondary to vascular pathology is the third leading cause of death in patients with LDS, with a prevalence of IAs estimated to range between $10 \%$ and $28 \% .^{33,45,55}$ In Marfan syndrome, aortic aneurysms and dissections are the most commonly associated vascular pathologies, and multiple reports suggest an association with IAs. Other syndromes outside of the classic connective tissue disorders are also associated with IAs in lower frequency, including neurofibromatosis type 1 (NF1). In addition to the well-characterized constellation of clinical criteria for NF1, IAs have been reported in up to $11 \%$ of patients; however, studies on prevalence are conflicting. ${ }^{18}$ Other studies have suggested an association between autosomal dominant mendelian disorders such as hereditary hemorrhagic telangiectasia, but have failed to demonstrate a prevalence of aneurysms that is higher than in the general population. ${ }^{12}$

Last, there are syndromes inherited in an autosomal recessive fashion or that arise from de novo genetic changes that have also been shown to be associated with IAs, although in lower frequency than the syndromes listed above. These include patients with pseudoxanthoma elasticum, which is associated with mutations in the $A B C C 6$ gene on chromosome $16 \mathrm{p} 13$. It has been posited that IAs in this syndrome may form as a result of abnormal elastic lamina in the intracranial vasculature, predominantly in the intracranial internal carotid artery. ${ }^{11,48}$ Finally, emerging evidence through WES suggests a role for the PCNT gene in cerebrovascular disease. This gene encodes a protein involved in microtubule nucleation and organization in the cell cycle, and biallelic loss-of-function mutations are known to cause microcephalic osteodysplastic primordial dwarfism type II. In more than half of cases, patients with point mutations in $P C N T$ are thought to develop IAs, and this genetic aberration may also confer a risk of developing multiple IAs in the same individual. ${ }^{42}$ Although these genetic aberrations provide clues to the basis of aneurysm formation, the risks associated with rupture in these individual syndromes remains to be determined.

\section{Polymorphic Variants and Respective Susceptibility Loci}

Identification of genetic variants contributing to the risk of formation and rupture of IAs beyond well-characterized mendelian syndromes has occurred largely through linkage analyses, GWAS to identify risk loci, candidate gene approaches and, more recently, whole-exome-based analyses. GWAS have served as the principal methodology for identifying genetic factors associated with IAs and have identified several risk loci and associated candidate genes in various ethnic patient cohorts, such as European, Finnish, Japanese, and French-Canadian populations. Risk loci and candidate genes include the following: $4 \mathrm{q} 31.22$ (EDNRA), 8q11.23 (SOX17), 7p21.1 (HDAC9), 9p21.323.1 (CDKN2A-CDKN2BAS), 11q13 (ARHGEF17), 13q13.1 (STARD13-KL), and 18q11.2 (RBBP8) (Table 2, p $\left.<1.0 \mathrm{e}^{-6}\right)$. $^{1,2,10,17,19,20,37,38,43,47,65,68,69}$ Many of these regions also overlap with population-based studies of Kazakh patients in smaller cohorts, which may be insufficient for genomewide discovery but useful for candidate-gene-based validation. ${ }^{72}$ A large locus encompassing numerous candidate genes on chromosome $19 \mathrm{q} 13$ has also been implicated. ${ }^{62}$ Further studies of French-Canadian families have identified additional novel genes and loci including FHIT (3p14, rs1554600, p = $4 \times 10^{-9}$ ) and CCDC80 (rs78125721, $\mathrm{p}=$ $\left.4.77 \times 10^{-7}\right),{ }^{74}$ as well as the $8 \mathrm{p} 23.1$ and $18 \mathrm{q} 11.2$ loci.

Additional polymorphic variants have been identified both in the above-mentioned studies and in others, although with a lower level of statistical significance. Accordingly, the expected role of these variants in the development of IAs is less robust, or may be more significant in the context of other regulatory variants. This includes other polymorphic variants in the aforementioned genes, including CDKN2BAS and SOX17, which are both recurrently implicated in IA formation across multiple studies. ${ }^{15}$ The first WES study of IAs examined 12 Japanese families, and only one variant in ADAMTS15 (rs185269810) reached a statistically significant association in both the initial and validation cohorts. ${ }^{67}$ Further supporting a role for ADAMTS genes, recent case-control studies and meta-analyses have further implicated polymorphisms in genes encoding matrix metalloproteases (MMPs) such as ADAMTS2 (rs11750568: OR 1.32, p = 0.006), as well as other ADAMTS family genes (ADAMTS12 variant rs1364044: OR 0.65, $\mathrm{p}=0.0001 ;$ ADAMTS13 variants rs739469 and rs4962153: OR 0.77 and $0.63, p=0.02$ and 0.0006 , respectively). ${ }^{3,8}$ Of the WES studies in the literature, there was no overlap between the variants in the implicated genes. ${ }^{67,73,76}$

It is important to note that numerous studies identify risk loci alone and require further functional validation in order to narrow the number of candidate causative genes at the respective chromosomal locus. However, there are implications for modifier alleles playing a role in intergenic regions that harbor regulatory elements. ${ }^{39}$

\section{Genetic Modifiers of Aneurysm Rupture and Subsequent Outcomes}

In addition to genetic variants underlying the presence or formation of IAs, there are rich data that can be mined to identify risk loci for aneurysmal rupture and clinical outcomes following aSAH. Following rupture, the genetics of this disease are further complicated by etiologies that may govern other dimensions of SAH care, including vasospasm, which has been regarded as a principal cause of devastating outcomes related to delayed cerebral ischemia (DCI). There is a dearth of studies reporting on this outcome and, of the few that exist in the literature, many are not sufficiently powered to draw robust conclusions. Studies of outcomes primarily report on gene expression profiles, which are inherently dynamic, rather than static genetic aberrations that may define a static measure of risk. ${ }^{9,63}$ 
TABLE 2. Literature review of polymorphic variants implicated in susceptibility of formation and rupture of IAs

\begin{tabular}{|c|c|c|c|c|}
\hline Authors \& Year & Gene & Locus & Variant Allele & OR $[95 \% \mathrm{Cl}]$ \\
\hline Chen et al., 2013 & ACE & $17 q 23.3$ & rs4646994 & $1.27[1.03-1.57]$ \\
\hline \multirow[t]{2}{*}{ Kurki et al., 2014} & \multirow[t]{2}{*}{ ANKRD44 } & \multirow[t]{2}{*}{$2 q 33$} & rs919433 & 1.25 (not reported) \\
\hline & & & rs12472355 & 1.24 (not reported) \\
\hline \multirow[t]{2}{*}{ Alg et al., 2013} & \multirow[t]{5}{*}{ ANRIL (CDKN2B-AS1) } & \multirow[t]{5}{*}{$9 \mathrm{p} 21$} & rs1333040 & $1.24[1.2-1.29]$ \\
\hline & & & rs10757278 & $1.29[1.21-1.38]$ \\
\hline Foroud et al., 2012 & & & rs6475606 & 1.35 (not reported) \\
\hline Foroud et al., 2014 & & & rs10733376 & $1.34[1.231 .45]$ \\
\hline Kurki et al., 2014 & & & rs1333042 & 1.32 (not reported) \\
\hline Yang et al., 2018 & ARHGEF17 & $11 q 13$ & rs2298808 & 6.6 [2.9-15.8] \\
\hline Yasuno et al., 2010 & CNNM2 & $10 q 24$ & rs124123409 & $1.29[1.19-1.40]$ \\
\hline \multirow[t]{3}{*}{ Alg et al., 2013} & COL1A2 & $7 q 21$ & rs42524 & $1.77[1.14-2.75]$ \\
\hline & COL1A3 & $2 q 32$ & rs1080255 & $1.55[1.21-2.00]$ \\
\hline & EDNRA & $4 q 31$ & rs6841581 & $1.22[1.14-1.31]$ \\
\hline Akagawa et al., 2006 & ELN & $7 q 11$ & rs8326 & $3.11[1.96-5.45]$ \\
\hline Lin et al., 2014 & ENG & $9 q 34$ & rs1800956 & $1.56[1.08-2.26]$ \\
\hline Kurki et al., 2014 & EPM2A & $6 q 24$ & rs75018213 & 2.11 (not reported) \\
\hline Alg et al., 2013 & FGD6 & $12 q 22$ & rs6538595 & $1.16[1.10-1.23]$ \\
\hline Kurki et al., 2014 & FSTL4 & $5 q 31$ & rs113816216 & 2.31 (not reported) \\
\hline Foroud et al., 2014 & HDAC9 & $7 \mathrm{p} 21$ & rs10230207 & $1.27[1.17-1.38]$ \\
\hline \multirow[t]{2}{*}{ Alg et al., 2013} & HSPG2 & $1 p 36$ & rs3767137 & $1.22[1.08-1.39]$ \\
\hline & IL6 & $7 p 15$ & rs1800796 & $0.47[0.34-0.65]$ \\
\hline Krischek et al., 2010 & JDP2 & $14 q 24$ & rs175646 & $1.44[1.15-1.81]$ \\
\hline Weinsheimer et al., 2007 & $K L K 8$ & $19 q 13$ & rs1722561 & $1.35[1.14-1.60]$ \\
\hline Low et al., 2011 & LIMK1 & $7 q 11$ & rs6460071 & $1.31[1.12-1.53]$ \\
\hline Kurki et al., 2014 & LYPD6 & $2 q 23$ & rs74972714 & 2.73 (not reported) \\
\hline \multirow[t]{2}{*}{ Foroud et al., 2012} & \multirow[t]{2}{*}{ PDE1A } & \multirow[t]{2}{*}{$2 q 33$} & rs1897472 & 1.78 (not reported) \\
\hline & & & rs3769801 & 1.79 (not reported) \\
\hline Bilguvar et al., 2008 & PLCL1 & $2 q 32$ & rs700675 & $1.22[1.13-1.32]$ \\
\hline Yasuno et al., 2010 & RBBP8 & $18 q 11$ & rs11661542 & $1.21[1.14-1.30]$ \\
\hline \multirow[t]{4}{*}{ Alg et al., 2013} & $R R B P 1$ & 20p12 & rs11332274 & $1.19[1.11-1.28]$ \\
\hline & SERPINA3 & $14 q 32$ & rs4934 & $2.22[1.68-2.94]$ \\
\hline & \multirow[t]{2}{*}{ SOX17 } & \multirow[t]{2}{*}{$8 q 11$} & rs10958409 & $1.20[1.15-1.26]$ \\
\hline & & & rs9298506 & $1.21[1.15-1.27]$ \\
\hline Bilguvar et al., 2008 & STARD13 & $13 q 13$ & rs9135204 & $1.20[1.13-1.28]$ \\
\hline
\end{tabular}

Complementary studies of variants have also identified the presence of aneurysms as well as subsets of patients with aneurysms that are more likely to rupture, including tandem repeats in endothelial nitric oxide synthase (eNOS/NOS3) polymorphisms, with an OR as high as 11.4 (95\% CI 1.7-75.9, $\mathrm{p}=0.004$ ) for individuals harboring 3 distinct variant alleles in this gene. ${ }^{30,31,52}$ Further studies of eNOS polymorphic variants have suggested an association between rs2070744 and DCI following aSAH; however, these results only reached borderline significance (OR 2.936, 95\% CI 1.048-8.226; $\mathrm{p}=0.040) .{ }^{24}$ Data from the same group also implicates a variant in $H M G B 1$ in DCI (rs2249825: OR 5.695, 95\% CI 1.804-17.975; $\mathrm{p}=0.003){ }^{25}$ Finally, there has been intensive investigation of $A P O E$ variants in candidate-gene-based studies and their impact on functional outcome in SAH. These studies have yielded mixed findings, with some reporting minor implications and others reporting no statistically significant associations. ${ }^{21,26,28,40,60}$

\section{Posited Mechanisms of Aneurysm Formation and Rupture Risk: Vascular Remodeling and Inflammation}

The syndromic disorder most strongly associated with IAs is ADPKD. ${ }^{56}$ Both genes implicated in this disease, $P K D 1$ and PKD2, are expressed in the smooth-muscle cells of the tunica media and myofibroblasts in blood vessels. ${ }^{23,61}$ Similarly, the role of collagen genes and genes in the TGF $\beta$ pathway in vascular remodeling is well established, although the exact mechanisms remain unclear. ${ }^{56}$ Of the aforementioned genetic variants that are highly statistically significant in polymorphisms identified through 
GWAS, the unifying theme of these genes is their role in vascular remodeling and endothelial maintenance. ${ }^{4}$ For example, $S O X 17$ is required for both endothelial formation and maintenance, whereas other genes such as $C D K N 2 B$ and ANRIL (noncoding), and STARD13 function in cell cycle regulation and progression. ${ }^{27,32,41,64}$ Accordingly, these genes may govern a balance in cell cycle regulation in the arterial wall. Similarly, MMP variants such as in the ADAMTS gene family also suggest that defects in these genes may compromise endothelial wall integrity and, coupled with inflammatory processes, may trigger vascular remodeling along the pathway of IA formation. ${ }^{8}$ The protein products of these genes are known to localize to dense plaques of intracranial arteries, which strongly supports their role in the development and maintenance of myoelastic arterial walls. ${ }^{56}$

Many of the identifying gene candidates are also involved in the inflammatory cascade, including MMPs, TGF $\beta$ proteins, and eNOS. ${ }^{14}$ Functionally, there is strong evidence to support a role for inflammatory reactions with aneurysm formation. In particular, an inflammatory response is triggered by endothelial dysfunction and compromised cell wall integrity. ${ }^{14}$ Such a model is supported whereby recruitment of inflammatory mediators to the cell wall disrupts the internal elastic lamina, initiating the formation process. Further damage to the cell wall resulting in cell death and degeneration ultimately predisposes to rupture. Similarly, mounting evidence suggests a role for NF- $x \mathrm{~B}$ as a critical mediator of cerebral aneurysm formation through its role in the inflammatory response in which macrophage recruitment and activation occur., ${ }^{6,53}$ Further supporting a role for the immune response in IA pathology and rupture risk, RNA sequencing studies have identified the lysosomal pathway and immunoglobulins in this context. $^{34}$

\section{Discussion}

This systematic review was aimed at comprehensively assessing and appraising the literature pertaining to the genetics of aneurysm formation and rupture risk. It is evident that there is significant heterogeneity with regard to the quality of studies, and among the rigorously designed studies, many report borderline statistical significance of candidate loci. Moreover, the literature is variable with regard to studies on this topic, and most pertain to the presence of IAs rather than genetic predictors of rupture and outcome risk. In the presence of known risk factors for rupture, genetic variables do not yet integrate into these algorithms. ${ }^{22}$ Similarly, there is also a lack of studies reporting on the association between aneurysmal rupture and gene-environment interactions. The natural history of IAs has been intensively studied, and modifiers of natural history in the context of genetic changes probably exist but remain to be discovered. Because these are polygenic traits, there is probably also some contribution of genetic predisposition in the presence of known risk factors for formation and rupture. Moreover, an important consideration is that there may exist genetic risk factors for IAs that overlap with other intracranial vascular lesions such as arteriovenous malformations. Arteriovenous malformations often have associated prenidal aneurysms, suggesting there may be a common basis to the pathophysiology of their formation. Meta-analyses have implicated SOX17 in this regard, and this is a highly recurrent gene in IA studies. ${ }^{36}$

The findings from this study highlight several important considerations, as well as implications for screening and future studies. Well-known syndromes associated with IAs are thought to arise secondary to dysfunction in genes that play a critical regulatory role in vessel formation. This is mirrored in the genes identified in GWAS and candidate gene analyses. There remains an important gap between the genetic risk of aneurysm formation and predictors of outcomes. Common converging themes include vascular remodeling and an associated inflammatory response. This may suggest an important role for immune-modifying medications in patients at high risk for aneurysm rupture on the basis of established clinical paradigms. ${ }^{22}$

Some study limitations should be noted. This study was limited in that only English-language studies were included, and may have missed other potentially significant variants in the non-English literature. Moreover, the study was restricted to reports on genetic changes, which may only represent the tip of the iceberg in our understanding of the molecular basis of IAs. As in other complex multigenic conditions, such as autoimmune disease or cancer, there may be a prominent role for epigenetic changes governing the pathophysiology of vasculature remodeling and IA formation risk..$^{11,75}$ In addition, although this study was oriented toward identifying putative genes in risk loci, it is possible that modifier alleles in intergenic regions may harbor regulatory elements that are of functional significance. ${ }^{39}$ Finally, our study specifically did not encompass analyses of gene expression. The extent to which variability in gene expression contributes to aneurysm risk is still unclear, but may provide some clues regarding underlying genetic dysfunction.

\section{Conclusions}

There is a sizeable body of literature implicating genetic mutations and polymorphisms in the pathogenesis of IAs, with a varying degree of quality. There are probably germline variants of differential penetrance that contribute to risk, and the extent of polygenic interactions remains to be determined. Several candidate genes warrant further investigation, and assessment of the clinical implications of the rationale for use of immune-modifying agents may be rooted in the genetics governing IAs. Future studies should be aimed at unbiased and genome-wide analyses investigating the role of new genes in aneurysm formation and rupture, and may provide important clues for putative biomarkers. Moving forward, development of prediction models that incorporate well-validated genetic changes are needed. With the currently available tools in this postgenomic era, genome-wide analyses of large cohorts of patients with IA is the direction that is necessary to further our understanding of the genetics of this complex disease entity.

\section{References}

1. Akagawa H, Tajima A, Sakamoto Y, Krischek B, Yoneyama 
T, Kasuya H, et al: A haplotype spanning two genes, ELN and LIMK1, decreases their transcripts and confers susceptibility to intracranial aneurysms. Hum Mol Genet 15:17221734,2006

2. Akiyama K, Narita A, Nakaoka H, Cui T, Takahashi T, Yasuno K, et al: Genome-wide association study to identify genetic variants present in Japanese patients harboring intracranial aneurysms. J Hum Genet 55:656-661, 2010

3. Alg VS, Ke X, Grieve J, Bonner S, Walsh DC, Bulters D, et al: Association of functional MMP-2 gene variant with intracranial aneurysms: case-control genetic association study and meta-analysis. Br J Neurosurg 32:255-259, 2018

4. Alg VS, Sofat R, Houlden H, Werring DJ: Genetic risk factors for intracranial aneurysms: a meta-analysis in more than 116,000 individuals. Neurology 80:2154-2165, 2013

5. AlNuaimi D, AlKetbi R, AlFalahi A, AlBastaki U, PierreJerome C: Ruptured berry aneurysm as the initial presentation of polycystic kidney disease: a case report and review of literature. J Radiol Case Rep 12:1-8, 2018

6. Aoki T, Fròsen J, Fukuda M, Bando K, Shioi G, Tsuji K, et al: Prostaglandin $\mathrm{E}_{2}-\mathrm{EP} 2-\mathrm{NF}-\boldsymbol{x B}$ signaling in macrophages as a potential therapeutic target for intracranial aneurysms. Sci Signal 10:eaah6037, 2017

7. Aoki T, Kataoka H, Shimamura M, Nakagami H, Wakayama $\mathrm{K}$, Moriwaki T, et al: NF- $x \mathrm{~B}$ is a key mediator of cerebral aneurysm formation. Circulation 116:2830-2840, 2007

8. Arning A, Jeibmann A, Köhnemann S, Brokinkel B, Ewelt $\mathrm{C}$, Berger K, et al: ADAMTS genes and the risk of cerebral aneurysm. J Neurosurg 125:269-274, 2016

9. Baumann A, Devaux Y, Audibert G, Zhang L, Bracard S, Colnat-Coulbois $\mathrm{S}$, et al: Gene expression profile of blood cells for the prediction of delayed cerebral ischemia after intracranial aneurysm rupture: a pilot study in humans. Cerebrovasc Dis 36:236-242, 2013

10. Bilguvar K, Yasuno K, Niemelä M, Ruigrok YM, von Und Zu Fraunberg M, van Duijn CM, et al: Susceptibility loci for intracranial aneurysm in European and Japanese populations. Nat Genet 40:1472-1477, 2008

11. Bock A, Schwegler G: Intracerebral haemorrhage as first manifestation of pseudoxanthoma elasticum. Clin Neurol Neurosurg 110:262-264, 2008

12. Brinjikji W, Iyer VN, Yamaki V, Lanzino G, Cloft HJ, Thielen KR, et al: Neurovascular manifestations of hereditary hemorrhagic telangiectasia: a consecutive series of 376 patients during 15 years. AJNR Am J Neuroradiol 37:14791486, 2016

13. Broderick JP, Brown RD Jr, Sauerbeck L, Hornung R, Huston J III, Woo D, et al: Greater rupture risk for familial as compared to sporadic unruptured intracranial aneurysms. Stroke 40:1952-1957, 2009

14. Chalouhi N, Ali MS, Jabbour PM, Tjoumakaris SI, Gonzalez LF, Rosenwasser RH, et al: Biology of intracranial aneurysms: role of inflammation. J Cereb Blood Flow Metab 32:1659-1676, 2012

15. Chen Y, Li G, Fan H, Guo S, Li R, Yin J, et al: CDKN2BAS gene polymorphisms and the risk of intracranial aneurysm in the Chinese population. BMC Neurol 17:214, 2017

16. Chen YL, Luo CB, Hsu SW, Rodesch G, Lasjaunias P: Tuberous sclerosis complex with an unruptured intracranial aneurysm: manifestations of contiguous gene syndrome. Interv Neuroradiol 7:337-341, 2001

17. Chen Z, Ma J, Cen Y, Liu Y, You C: The angiotensin converting enzyme insertion/deletion polymorphism and intracranial aneurysm: a meta-analysis of case-control studies. Neurol India 61:293-299, 2013

18. Conway JE, Hutchins GM, Tamargo RJ: Lack of evidence for an association between neurofibromatosis type I and intracranial aneurysms: autopsy study and review of the literature. Stroke 32:2481-2485, 2001
19. Foroud T, Koller DL, Lai D, Sauerbeck L, Anderson C, Ko $\mathrm{N}$, et al: Genome-wide association study of intracranial aneurysms confirms role of Anril and SOX17 in disease risk. Stroke 43:2846-2852, 2012

20. Foroud T, Lai D, Koller D, Van't Hof F, Kurki MI, Anderson $\mathrm{CS}$, et al: Genome-wide association study of intracranial aneurysm identifies a new association on chromosome 7. Stroke 45:3194-3199, 2014

21. Gallek MJ, Conley YP, Sherwood PR, Horowitz MB, Kassam A, Alexander SA: APOE genotype and functional outcome following aneurysmal subarachnoid hemorrhage. Biol Res Nurs 10:205-212, 2009

22. Greving JP, Wermer MJ, Brown RD Jr, Morita A, Juvela S, Yonekura M, et al: Development of the PHASES score for prediction of risk of rupture of intracranial aneurysms: a pooled analysis of six prospective cohort studies. Lancet Neurol 13:59-66, 2014

23. Griffin MD, Torres VE, Grande JP, Kumar R: Vascular expression of polycystin. J Am Soc Nephrol 8:616-626, 1997

24. Hendrix P, Foreman PM, Harrigan MR, Fisher WS III, Vyas NA, Lipsky RH, et al: Endothelial nitric oxide synthase polymorphism is associated with delayed cerebral ischemia following aneurysmal subarachnoid hemorrhage. World Neurosurg 101:514-519, 2017

25. Hendrix P, Foreman PM, Harrigan MR, Fisher WSR, Vyas NA, Lipsky RH, et al: Impact of high-mobility group box 1 polymorphism on delayed cerebral ischemia after aneurysmal subarachnoid hemorrhage. World Neurosurg 101:325-330, 2017

26. Hu X, Xie Z, Zan X, Ma L, Li H, You C, et al: Role of apolipoprotein $\mathrm{E}$ genotypes in aneurysmal subarachnoid hemorrhage: susceptibility, complications, and prognosis. World Neurosurg 118:e666-e676, 2018

27. Janzen V, Forkert R, Fleming HE, Saito Y, Waring MT, Dombkowski DM, et al: Stem-cell ageing modified by the cyclin-dependent kinase inhibitor p16INK4a. Nature 443:421-426, 2006

28. Juvela S, Siironen J, Lappalainen J: Apolipoprotein E genotype and outcome after aneurysmal subarachnoid hemorrhage. J Neurosurg 110:989-995, 2009

29. Kanne JP, Talner LB: Autosomal dominant polycystic kidney disease presenting as subarachnoid hemorrhage. Emerg Radiol 11:110-112, 2004

30. Khurana VG, Meissner I, Meyer FB: Update on genetic evidence for rupture-prone compared with rupture-resistant intracranial saccular aneurysms. Neurosurg Focus 17(5):E7, 2004

31. Khurana VG, Meissner I, Sohni YR, Bamlet WR, McClelland RL, Cunningham JM, et al: The presence of tandem endothelial nitric oxide synthase gene polymorphisms identifying brain aneurysms more prone to rupture. J Neurosurg 102:526-531, 2005

32. Kim I, Saunders TL, Morrison SJ: Sox17 dependence distinguishes the transcriptional regulation of fetal from adult hematopoietic stem cells. Cell 130:470-483, 2007

33. Kim ST, Brinjikji W, Kallmes DF: Prevalence of intracranial aneurysms in patients with connective tissue diseases: a retrospective study. AJNR Am J Neuroradiol 37:1422-1426, 2016

34. Kleinloog R, Verweij BH, van der Vlies P, Deelen P, Swertz MA, de Muynck L, et al: RNA sequencing analysis of intracranial aneurysm walls reveals involvement of lysosomes and immunoglobulins in rupture. Stroke 47:1286-1293, 2016

35. Korja M, Silventoinen K, McCarron P, Zdravkovic S, Skytthe A, Haapanen A, et al: Genetic epidemiology of spontaneous subarachnoid hemorrhage: Nordic Twin Study. Stroke 41:2458-2462, 2010

36. Kremer PH, Koeleman BP, Pawlikowska L, Weinsheimer S, Bendjilali N, Sidney S, et al: Evaluation of genetic risk loci 
for intracranial aneurysms in sporadic arteriovenous malformations of the brain. J Neurol Neurosurg Psychiatry 86:524-529, 2015

37. Krischek B, Tajima A, Akagawa H, Narita A, Ruigrok Y, Rinkel G, et al: Association of the Jun dimerization protein 2 gene with intracranial aneurysms in Japanese and Korean cohorts as compared to a Dutch cohort. Neuroscience 169:339-343, 2010

38. Kurki MI, Gaál EI, Kettunen J, Lappalainen T, Menelaou A, Anttila V, et al: High risk population isolate reveals low frequency variants predisposing to intracranial aneurysms. PLoS Genet 10:e1004134, 2014

39. Laarman MD, Vermunt MW, Kleinloog R, de Boer-Bergsma JJ, Brain Bank N, Rinkel GJE, et al: Intracranial aneurysmassociated single-nucleotide polymorphisms alter regulatory DNA in the human circle of Willis. Stroke 49:447-453, 2018

40. Leung CH, Poon WS, Yu LM, Wong GK, Ng HK: Apolipoprotein e genotype and outcome in aneurysmal subarachnoid hemorrhage. Stroke 33:548-552, 2002

41. Leung TH, Ching YP, Yam JW, Wong CM, Yau TO, Jin DY, et al: Deleted in liver cancer 2 (DLC2) suppresses cell transformation by means of inhibition of RhoA activity. Proc Natl Acad Sci US A 102:15207-15212, 2005

42. Li FF, Wang XD, Zhu MW, Lou ZH, Zhang Q, Zhu CY, et al: Identification of two novel critical mutations in PCNT gene resulting in microcephalic osteodysplastic primordial dwarfism type II associated with multiple intracranial aneurysms. Metab Brain Dis 30:1387-1394, 2015

43. Lin Y, Yu H, Song W, Zhang Y, Zhang C, Zhu Y, et al: A variant in the endoglin gene is associated with the development of sporadic intracranial aneurysms. Curr Neurovasc Res 11:294-301, 2014

44. Loeys BL, Chen J, Neptune ER, Judge DP, Podowski M, Holm T, et al: A syndrome of altered cardiovascular, craniofacial, neurocognitive and skeletal development caused by mutations in TGFBR1 or TGFBR2. Nat Genet 37:275-281, 2005

45. Loeys BL, Schwarze U, Holm T, Callewaert BL, Thomas GH, Pannu H, et al: Aneurysm syndromes caused by mutations in the TGF- $\beta$ receptor. N Engl J Med 355:788-798, 2006

46. Longa L, Scolari F, Brusco A, Carbonara C, Polidoro S, Valzorio B, et al: A large TSC2 and PKD1 gene deletion is associated with renal and extrarenal signs of autosomal dominant polycystic kidney disease. Nephrol Dial Transplant 12:1900-1907, 1997

47. Low SK, Zembutsu H, Takahashi A, Kamatani N, Cha PC, Hosono N, et al: Impact of LIMK1, MMP2 and TNF- $\alpha$ variations for intracranial aneurysm in Japanese population. J Hum Genet 56:211-216, 2011

48. Munyer TP, Margulis AR: Pseudoxanthoma elasticum with internal carotid artery aneurysm. AJR Am J Roentgenol 136:1023-1024, 1981

49. Nadeau JH: Modifier genes in mice and humans. Nat Rev Genet 2:165-174, 2001

50. Niemczyk M, Gradzik M, Fliszkiewicz M, Kulesza A, Gołębiowski M, Pączek L: Natural history of intracranial aneurysms in autosomal dominant polycystic kidney disease. Neurol Neurochir Pol 51:476-480, 2017

51. Nieuwkamp DJ, Setz LE, Algra A, Linn FH, de Rooij NK, Rinkel GJ: Changes in case fatality of aneurysmal subarachnoid haemorrhage over time, according to age, sex, and region: a meta-analysis. Lancet Neurol 8:635-642, 2009

52. Paschoal EHA, Yamaki VN, Teixeira RKC, Paschoal Junior FM, Jong-A-Liem GS, Teixeira MJ, et al: Relationship between endothelial nitric oxide synthase (eNOS) and natural history of intracranial aneurysms: meta-analysis. Neurosurg Rev 41:87-94, 2018

53. Pawlowska E, Szczepanska J, Wisniewski K, Tokarz P, Jaskólski DJ, Blasiak J: NF- $x$ B-mediated inflammation in the pathogenesis of intracranial aneurysm and subarachnoid hemorrhage. Does autophagy play a role? Int J Mol Sci 19:E1245, 2018

54. Rinkel GJ, Djibuti M, Algra A, van Gijn J: Prevalence and risk of rupture of intracranial aneurysms: a systematic review. Stroke 29:251-256, 1998

55. Rodrigues VJ, Elsayed S, Loeys BL, Dietz HC, Yousem DM: Neuroradiologic manifestations of Loeys-Dietz syndrome type 1. AJNR Am J Neuroradiol 30:1614-1619, 2009

56. Rossetti S, Harris PC: The genetics of vascular complications in autosomal dominant polycystic kidney disease (ADPKD). Curr Hypertens Rev 9:37-43, 2013

57. Ruigrok YM, Elias R, Wijmenga C, Rinkel GJ: A comparison of genetic chromosomal loci for intracranial, thoracic aortic, and abdominal aortic aneurysms in search of common genetic risk factors. Cardiovasc Pathol 17:40-47, 2008

58. Schievink WI, Michels VV, Piepgras DG: Neurovascular manifestations of heritable connective tissue disorders. A review. Stroke 25:889-903, 1994

59. Shi C, Awad IA, Jafari N, Lin S, Du P, Hage ZA, et al: Genomics of human intracranial aneurysm wall. Stroke 40:1252-1261, 2009

60. Tang J, Zhao J, Zhao Y, Wang S, Chen B, Zeng W: Apolipoprotein $\mathrm{E} \varepsilon 4$ and the risk of unfavorable outcome after aneurysmal subarachnoid hemorrhage. Surg Neurol 60:391-397, 2003

61. Torres VE, Cai Y, Chen X, Wu GQ, Geng L, Cleghorn KA, et al: Vascular expression of polycystin-2. J Am Soc Nephrol 12:1-9, 2001

62. van der Voet M, Olson JM, Kuivaniemi H, Dudek DM, Skunca M, Ronkainen A, et al: Intracranial aneurysms in Finnish families: confirmation of linkage and refinement of the interval to chromosome 19q13.3. Am J Hum Genet 74:564-571, 2004

63. Vergouwen MD, Frijns CJ, Roos YB, Rinkel GJ, Baas F, Vermeulen M: Plasminogen activator inhibitor-1 4G allele in the $4 \mathrm{G} / 5 \mathrm{G}$ promoter polymorphism increases the occurrence of cerebral ischemia after aneurysmal subarachnoid hemorrhage. Stroke 35:1280-1283, 2004

64. Visel A, Zhu Y, May D, Afzal V, Gong E, Attanasio C, et al: Targeted deletion of the 9p21 non-coding coronary artery disease risk interval in mice. Nature 464:409-412, 2010

65. Weinsheimer S, Goddard KA, Parrado AR, Lu Q, Sinha M, Lebedeva ER, et al: Association of kallikrein gene polymorphisms with intracranial aneurysms. Stroke 38:2670-2676, 2007

66. Xu HW, Yu SQ, Mei CL, Li MH: Screening for intracranial aneurysm in 355 patients with autosomal-dominant polycystic kidney disease. Stroke 42:204-206, 2011

67. Yan J, Hitomi T, Takenaka K, Kato M, Kobayashi H, Okuda $\mathrm{H}$, et al: Genetic study of intracranial aneurysms. Stroke 46:620-626, 2015

68. Yang X, Li J, Fang Y, Zhang Z, Jin D, Chen X, et al: Rho guanine nucleotide exchange factor $A R H G E F 17$ is a risk gene for intracranial aneurysms. Circ Genom Precis Med 11:e002099, 2018

69. Yasuno K, Bilguvar K, Bijlenga P, Low SK, Krischek B, Auburger G, et al: Genome-wide association study of intracranial aneurysm identifies three new risk loci. Nat Genet 42:420-425, 2010

70. Yoneyama T, Kasuya H, Onda H, Akagawa H, Jinnai N, Nakajima T, et al: Association of positional and functional candidate genes FGF1, FBN2, and LOX on 5q31 with intracranial aneurysm. J Hum Genet 48:309-314, 2003

71. Yu L, Wang J, Wang S, Zhang D, Zhao Y, Wang R, et al: DNA methylation regulates gene expression in intracranial aneurysms. World Neurosurg 105:28-36, 2017

72. Zholdybayeva EV, Medetov YZ, Aitkulova AM, Makhambetov YT, Akshulakov SK, Kaliyev AB, et al: Genetic risk 
factors for intracranial aneurysm in the Kazakh population. $\mathbf{J}$ Mol Neurosci 66:135-145, 2018

73. Zhou S, Ambalavanan A, Rochefort D, Xie P, Bourassa CV, Hince P, et al: RNF213 is associated with intracranial aneurysms in the French-Canadian population. Am J Hum Genet 99:1072-1085, 2016

74. Zhou S, Gan-Or Z, Ambalavanan A, Lai D, Xie P, Bourassa $\mathrm{CV}$, et al: Genome-wide association analysis identifies new candidate risk loci for familial intracranial aneurysm in the French-Canadian population. Sci Rep 8:4356, 2018

75. Zhou S, Gao X, Sun J, Lin Z, Huang Y: DNA methylation of the PDGFD gene promoter increases the risk for intracranial aneurysms and brain arteriovenous malformations. DNA Cell Biol 36:436-442, 2017

76. Karasozen Y, Osbun JW, Parada CA, Busald T, Tatman P, Gonzalez-Cuyar LF, et al: Somatic PDGFRB activating variants in fusiform cerebral aneurysms. Am J Hum Genet 104:968-976, 2019

\section{Disclosures}

The authors report no conflict of interest concerning the materials or methods used in this study or the findings specified in this paper.

\section{Author Contributions}

Conception and design: both authors. Acquisition of data: Samuel. Analysis and interpretation of data: both authors. Drafting the article: both authors. Critically revising the article: both authors. Reviewed submitted version of manuscript: both authors Approved the final version of the manuscript on behalf of both authors: Radovanovic. Statistical analysis: both authors. Administrative/technical/material support: Radovanovic. Study supervision: both authors.

\section{Correspondence}

Ivan Radovanovic: Toronto Western Hospital, University Health Network, Toronto, ON, Canada.ivan.radovanovic@uhn.ca. 